\title{
Estimativa 2018: Incidência de Câncer no Brasil
}

\author{
Estimate 2018: Cancer Incidence in Brazil \\ Estimación 2018: Incidencia de Cáncer en Brasil
}

Instituto Nacional de Câncer José Alencar Gomes da Silva. Estimativa 2018: incidência de câncer no Brasil. Rio de Janeiro: INCA, 2017. 128 p. ISBN 978-85-7318-362-7 (versão impressa) ISBN 978-85-7318-361-0 (versão eletrônica)

Marceli de Oliveira Santos'

Desde1995, o INCA elabora e publica a Estimativa de Câncer. Até o ano de 2003, a publicação incluía a estimativa da mortalidade, entretanto, com a evolução do Sistema de Informação sobre Mortalidade (SIM) e sua atualidade, não foi mais necessário fazê-la.

O ano de 2000 marcou a divulgação da estimativa de casos novos desagregados por Unidades da Federação e o Distrito Federal. A partir de 2001, a publicação passou a incluir também as capitais. Ainda hoje, o Brasil é o único país da América Latina que divulga continuamente a estimativa com desagregação por suas Regiōes, Estados, Distrito Federal e capitais. A partir do ano de 2006, a estimativa passou a ter periodicidade bienal.

A estimativa fornece um diagnóstico da situação atual dos casos novos de câncer, subsidiando gestores, serviços de saúde, universidades, centros de pesquisa, sociedades científicas, entre outros, com informaçóes sobre o impacto e o perfil da doença na população.

Essa estimativa de casos novos de câncer apresenta, de forma inédita, as taxas de incidência ajustadas por idade; medida que tem por objetivo eliminar o impacto da distribuição etária populacional e, assim, permitir comparaçôes tanto regionais quanto internacionais.

Estima-se, no biênio 2018-2029, a ocorrência de 600 mil casos novos de câncer. Excetuando-se o câncer de pele não melanoma (cerca de 170 mil casos novos), ocorrerão 420 mil casos novos de câncer. Os cânceres de próstata (68 mil) em homens e mama (60 mil) em mulheres serão os mais frequentes. À exceção do câncer de pele não melanoma, os tipos de câncer mais frequentes em homens serão próstata $(31,7 \%)$, pulmão $(8,7 \%)$, intestino $(8,1 \%)$, estômago $(6,3 \%)$ e cavidade oral $(5,2 \%)$. Nas mulheres, os cânceres de mama (29,5\%), intestino (9,4\%), colo do útero $(8,1 \%)$, pulmão $(6,2 \%)$ e tireoide $(4,0 \%)$ figurarão entre os principais.

As estimativas apresentadas para o Brasil refletem o perfil semelhante ao de países desenvolvidos, entretanto, ainda convive com altas taxas de cânceres, associados a infecçôes, que são característicos de países em desenvolvimento. Esse perfil é reflexo das desigualdades regionais tão peculiares ao Brasil, que vão desde as diferenças na expectativa de vida, condiçóes socioeconômicas, até o acesso aos serviços de saúde para diagnóstico oportuno e tratamento adequado.

A distribuição da incidência por região geográfica mostra que as Regiôes Sul e Sudeste concentram 70\% da incidência, e o padrão dos cânceres assemelha-se ao de países desenvolvidos onde os tipos predominantes são próstata, mama feminina, pulmão e cólon e reto. Destaca-se na Região Sul a alta incidência de câncer de pulmão, especialmente no Rio Grande do Sul. A Regiáo Norte apresenta a menor magnitude, entretanto, o padrão assemelha-se aos países menos desenvolvidos com os cânceres do colo do útero e de estômago entre os mais incidentes. Os Estados do Amazonas, Amapá e Maranhão têm a incidência de câncer do colo do útero semelhante aos países menos desenvolvidos.

De forma global, as taxas de incidência ajustadas por idade tanto em homens (217,27/100 mil) quanto em mulheres (191,78/100 mil) são consideradas intermediárias e compatíveis com as apresentadas para países em desenvolvimento. Existe, entretanto, uma alta variação regional. Nas regióes brasileiras mais desenvolvidas (Sul, Sudeste e Centro-Oeste), predominam em homens os cânceres de próstata, colorretal e pulmão, sendo as Regiốes Centro-Oeste e Sul as que apresentam as maiores

${ }^{1}$ Doutora em Saúde Coletiva. Departamento de Medicina Preventiva e Social da Universidade Estadual de Campinas. Tecnologista do Instituto Nacional de Câncer José Alencar Gomes da Silva (INCA).

Endereço para correspondência: Rua Marques de Pombal, 125 - Centro. Rio de Janeiro (RJ), Brasil. CEP 20230-240. E-mail: msantos@inca.gov.br. 
taxas ajustadas para câncer de próstata, semelhante às estimadas para as Regiôes mais desenvolvidas do mundo. É bastante provável que essas projeçôes, a exemplo dos países desenvolvidos, sejam reflexo do "superdiagnóstico" e não de um aumento real. Já o câncer colorretal nessas três regiôes apresenta taxas semelhantes à média mundial, porém acima da estimativa para a América do Sul. Destaca-se ainda que, diferentemente das demais Regiōes, o câncer de esôfago na Regiáo Sul figura entre os mais incidentes. Nas Regiōes menos desenvolvidas (Norte e Nordeste), o câncer de próstata também é o mais incidente, entretanto, o câncer de estômago está entre os três mais incidentes nessas regiôes, com taxas ajustadas semelhantes às de países menos desenvolvidos. $\mathrm{Na}$ Regiáo Norte, é o segundo mais incidente e, na Região Nordeste, o terceiro.

Ao analisar o perfil das mulheres, as desigualdades também se acentuam, impondo, às regiōes menos desenvolvidas, a carga de cânceres preveníveis e curáveis. A Região Norte do Brasil é a única onde o câncer do colo do útero tem a maior magnitude, com taxas ajustadas bem maiores do que a média mundial e semelhantes às da América Central. Na Região Nordeste, ainda que o câncer de mama seja mais incidente, as taxas ajustadas superam a média mundial e assemelham-se às regiốes menos desenvolvidas. As Regióes Sul e Sudeste apresentam perfil bastante diferenciado, com os cânceres de mama, colón e reto, e pulmão entre os mais incidentes, aproximando-se mais do perfil dos países desenvolvidos.

Essa mesma análise pode ser estendida aos Estados brasileiros onde as desigualdades também se apresentam. O Estado do Amazonas possui incidência de câncer do colo do útero semelhante à da África Oriental, um dos locais menos desenvolvidos do mundo. Amapá, Maranhão e Tocantins também têm perfil parecido com o das Regiôes Africanas, porém um pouco mais desenvolvidas (Sul e Centro da África). Além disso, todos os Estados das Regiôes Norte, Nordeste e Centro-Oeste (exceto o Distrito Federal) possuem perfil de incidência global semelhante aos países menos desenvolvidos. Somente os Estados da Regiấo Sudeste têm perfil comparável ao dos países mais desenvolvidos.

A estimativa é uma ferramenta de gestáo imprescindível para o delineamento e a organizaçáo da linha de cuidado do câncer, bem como para definir estratégias para atuar junto aos principais fatores de risco. É fundamental que sejam enfrentados os óbitos precoces e a ocorrência de cânceres preveníveis. A vigilância é um componente estratégico para o planejamento efetivo e eficiente das açóes e controle de câncer, para o monitoramento e a avaliação de seu desempenho. Somente a utilização de todos os instrumentos disponíveis possibilitará que se atinja os objetivos postos pela Organização Mundial da Saúde (OMS) para o enfrentamento do câncer: - prevenir o que for prevenível, evitando e reduzindo a exposição aos fatores de risco; curar o que for curável, com detecção precoce e estratégias para diagnóstico e tratamento; - alívio da dor e melhoria da qualidade de vida, com cuidados paliativos e; - gestấo para o sucesso, pelo fortalecimento da gestấo nacional, monitoramento e avaliação das estratégias de capacitação.

\section{REFERÊNCIAS}

1. Ferlay J, Soerjomataram I, Ervik M, Dikshit R, Eser S, Mathers C, Rebelo M, Parkin DM, Forman D, Bray, F. GLOBOCAN 2012: cancer incidence and mortality worldwide. [Internet]. Lyon: IARC; 2013. [acesso em 2018 maio 8]. Disponível em: http://globocan.iarc.fr

2. World Health Organization (WHO). The World Health Organization's fight against cancer: strategies that prevent, cure and care. Geneva: WHO Press; 2007. 